\title{
Bone Augmentation Procedures in Implantology
}

\author{
Vinay V. Kumar, Supriya Ebenezer, and Andreas Thor
}

\subsection{Introduction}

Dental implants have been used successfully to rehabilitate patients with edentulousness. For implant dentistry to be successful, the implants have to be placed in an appropriate threedimensional manner that supports the prosthesis adequately. This means that implants have to be placed in a prosthodontically driven predetermined position. This requirement often results in a clinical situation where there is a lack of bone volume to completely embed the implant in an ideal position.

Implants that do not have an adequate amount of bone covering them in all aspects (at least $1.5 \mathrm{~mm}$ bone buccal and lingual to the implant shoulder or about $2 \mathrm{~mm}$ in aesthetic zones) are at high risk for crestal bone loss with concomitant inflammation and infection of the surrounding soft tissues due to exposure and colonisation of the implant surfaces by bacterial biofilms [1]. This in turn results in soft-tissue recession, which leads to further loss of bone and eventually failure of the implant. Hence, bone augmentation is often necessary to ensure adequate bony housing around implants [2].

The most commonly used bone-augmentation surgical procedures are guided bone regeneration (GBR), block bone grafting and maxillary sinus floor elevation (SFE). When deciding to augment, there are multiple sources of bone-augmentation materials ranging from autogenous, allogenic, xenogenic and synthetic materials. A knowledge of these materials is essential prior to undertaking augmentation procedures. Knowledge of bone biology and bone physiology is also important.

Electronic Supplementary Material The online version of this chapter (https://doi.org/10.1007/978-981-15-1346-6_19) contains supplementary material, which is available to authorized users.

V. V. Kumar $(\bowtie) \cdot$ A. Thor

Department of Maxillofacial and Plastic Surgery,

Uppsala University Hospital, Uppsala, Sweden

S. Ebenezer

Department of Oral Surgery and Stomatology, University of Bern, Bern, Switzerland
It is obvious that a thorough medical history should be obtained before implant treatment and prior to augmentation procedures. Patients should be evaluated regarding their general health status, medical history, history of any medication, allergies, the use of tobacco and compliance to oral hygiene methods. Patients with conditions that affect bone healing would be poor candidates for augmentation procedures. Patients with a history of head and neck radiotherapy, uncontrolled diabetes, transplant patients undergoing prolonged immunotherapy, patients undergoing bisphosphonate therapy or medications that could induce osteonecrosis of the jaws, heavy smokers and patients with neuropsychiatric disorders are high-risk patients to undergo augmentation.

It is also obvious that prior to undertaking augmentation procedures, adequate radiographic assessment of the region should be performed. In most situations, Cone Beam Computed Tomography (CBCT) is the imaging of choice.

The use of tilted or angulated implants, narrow implants, zygomatic implants, short implants or the use of nonimplant-supported prosthesis can avoid the need for augmentations, and this should be discussed with the patient prior to undertaking augmentation surgery $[3,4]$.

\subsection{The Alveolar Bone-Resorption Pattern and the Need for Augmentation}

The alveolar bone is functionally and macroscopically unique. It is that functional area of the maxilla and mandible that is responsible for the anchorage of teeth. Both the mandible and the maxilla are irregular bones and are of mesenchymal origin. The maxilla consists for the most part of cancellous bone with a thin cortex layer, whereas the mandible has more cortical bone and is denser. As the alveolar process of the maxilla and mandible are basically functional components to support the teeth, after tooth loss, the alveolar bone starts to resorb. However, the pattern of bone resorption in the two bones is different. The maxillary alveolar bone 
resorbs from the labial plate inwards and the mandibular alveolar bone from the lingual plate outwards. Therefore, in the cases of long-standing edentulousness, this resorption pattern results in a narrower maxilla and mandible. The bone height is also reduced in a vertical direction in areas of tooth loss, leading to a reduced alveolar bone height in the maxillary posterior area (beneath the sinuses) and a reduced distance from the crest to the mandibular canal in the posterior mandible. The sagittal relation is also affected due to jaw atrophy, leading to an often retrognathic maxilla in relation to the wider mandible. In short, both the width of the bone (also called the volume of bone) and the quality of bone (described by Lekholm \& Zarb and Cawood \& Howell), [5, 6] must be taken into consideration before implant placement. Additionally, due to ridge resorption, the vertical and sagittal bone relations between the upper and lower jawbones and the toothless space must be taken into consideration before implant placement and bone augmentation, when treatment is planned from a prosthodontic point of view. Figure 19.1 shows the changes in edentulous jaws and the classification of bone quality and bone quantity as described by Lekholm and Zarb, 1985.

Also, in patients with tooth loss secondary to other reasons of bone loss such as trauma, pathologies, etc.; bone should be replaced to reconstruct the lost tissue as well as to support placement of implants in the best prosthetically driven position.

\subsection{Bone Biology}

Depending on the macroscopic form and mechanical function, bone can be designated as cancellous bone (also called spongiosa or trabecular bone) and cortical bone (also called compact bone). Cortical bone is the dense outer aspect of bone that is responsible for the mechanical strength. The inner cancellous part of the bone that predominantly consists of bone marrow and provides nutrition to the bone [7].

Microscopically cortical bone consists of concentric circles of osteons (also known as Haversian systems) (Fig. 19.2). Each osteon consists of a central canal of nerves and blood vessels that is surrounded by layers of compact bone. Microscopically, cancellous bone architecture consists of bone organised into a three-dimensional lattice framework called trabeculae. The trabecular spaces are filled with blood vessels and marrow. Bone marrow is a specialised connective tissue that produces erythrocytes, leucocytes, platelets and osteoblasts. Depending on age and location, bone marrow additionally contains fat cells and other connective tissue elements [8].

Under higher magnification, bone can be further designated as woven or lamellar bone. Woven bone is immature bone that forms following injury to mature bone (such as fractures or tooth extraction) or during the foetal growth period. After an injury to mature bone that causes a break in its continuity such as tooth extraction, a haematoma results and following this woven bone is formed rapidly to fill the defect in the bone. This bone is mechanically weak and its collagen fibrils have a random orientation. Woven bone is then replaced by mature and mechanically strong lamellar bone that has collagen fibrils arranged parallelly and regularly into distinct layers.

Bones of the human body are in a constant state of renewal, the process known as bone remodelling. Bone remodelling is essential to regulate mineral balance in the bone and circulatory system, as well as to maintain bone strength. Regular day stress and strain causes microdamage in bone, which is repaired and replaced by new bone by the
Fig. 19.1 Classification of bone for implant placement by Lekholm and Zarb, 1985. Adapted from Lekholm and Zarb, 1985 [6]
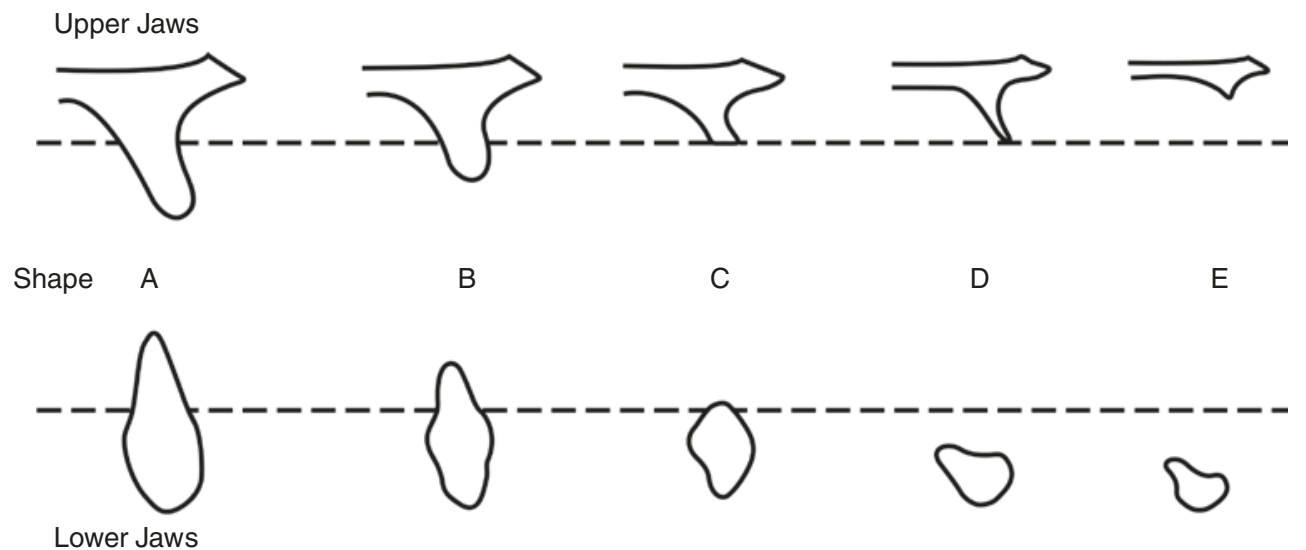

Lower Jaws
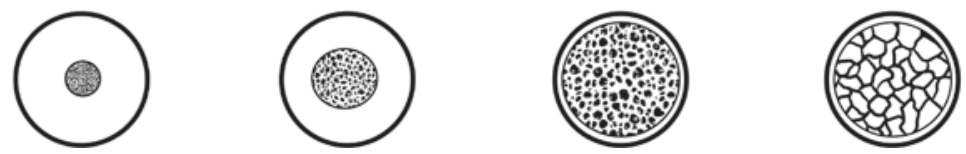

(C)Association of Oral and Maxillofacial Surgeons of India 
Fig. 19.2 Cross-section of bone showing a cortical bone and spongy/cancellous bone. Please note the osteon containing a central canal with blood vessels and nerves surrounded by concentric lamellae with osteocytes and lacunae

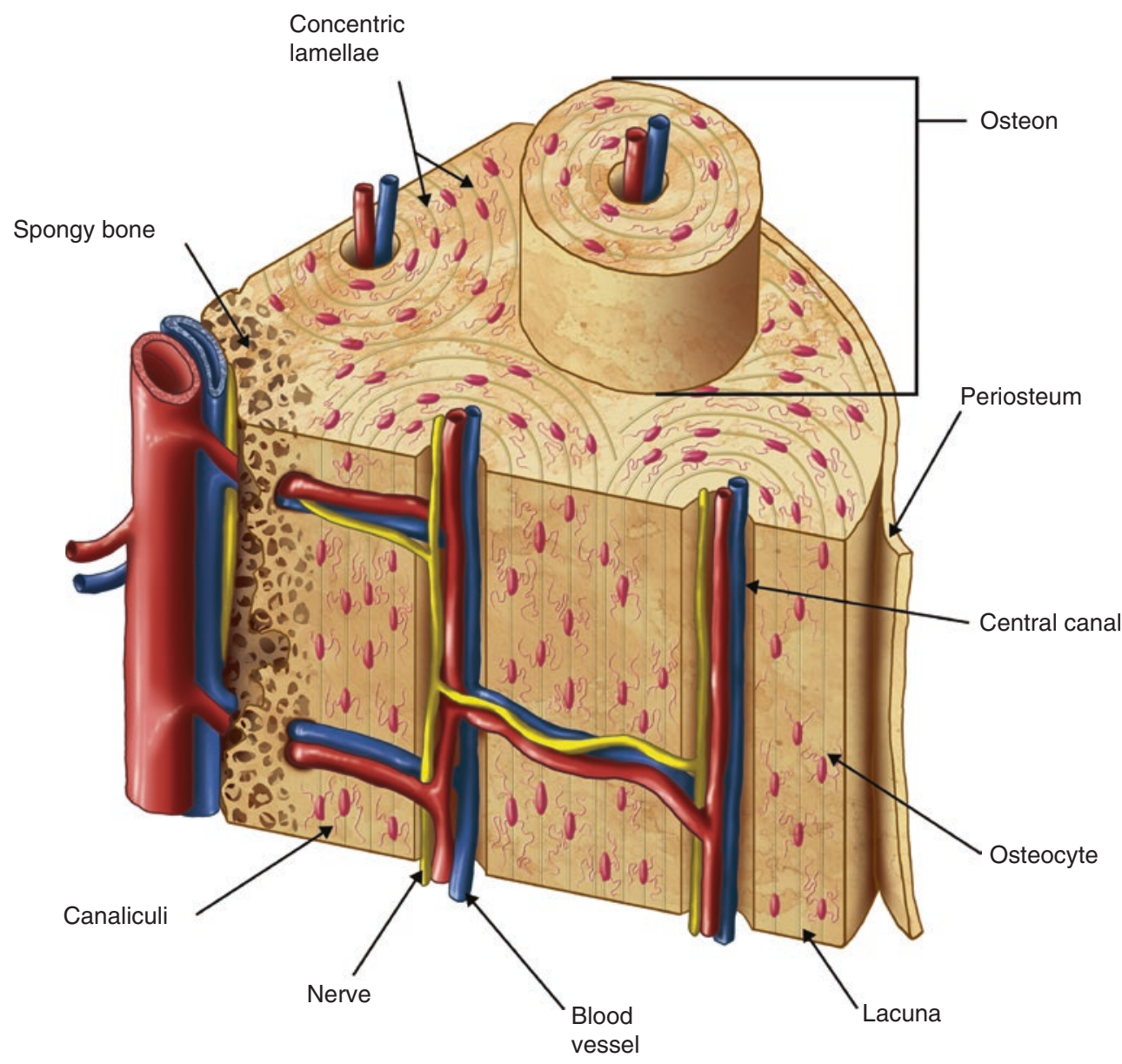

CAssociation of Oral and Maxillofacial Surgeons of India process of bone remodelling. Therefore, the process of bone remodelling helps the bone to adapt to changing mechanical and biologic needs during the lifetime of the individual. For the ease of description, bone remodelling can be divided as consisting of four continuous stages:

bone resorption,

reversal phase,

mineralisation phase

and resting phase (Fig. 19.3).

During the resorption phase, specialised cells called osteoblasts are activated, which eat away old bone. In the reversal phase, bone-forming cells known as osteoblasts begin to appear on the surface of the resorbed bone. In the bone-formation phase, the osteoblasts lay down osteoid, which is the unmineralised organic portion of bone and bone mineralisation occurs when calcium hydroxyapatite and other minerals are incorporated into the organic unmineralised osteoid, thereby providing mechanical strength. Bone remodelling occurs all throughout life and consists of a closely coupled phenomenon of bone apposition and resorp- tion. Under normal healthy conditions in adults, bone resorption and apposition during remodelling are balanced in time, space and amount so that the bone mass of the body remains more or less constant.

\subsubsection{Composition of Bone}

Bone is a connective tissue that consists of bone cells (approximately 10\%) in a connective tissue matrix (approximately $90 \%$ ). Cells of the bone are the osteoblasts, the osteocytes and osteoclasts. The osteoblasts are large uninucleate cells that form bone. They work in groups and predominantly lay down the collagen matrix known as osteoid. Osteoblasts also produce proteins such as bone morphogenetic proteins that stimulate bone healing and mineralisation. About $10 \%$ of the osteoblasts become entrapped inside the calcified bone matrix and are known as Osteocytes. Osteocytes reside in small bone cavities known as lacunae and are interconnected with each other and with osteoblasts and lining cells on the bone surface. Osteoclasts, on the other hand, are multinucleated cells that line the surface of the bone where resorption takes place. 
Fig. 19.3 describes the four phases of bone remodelling

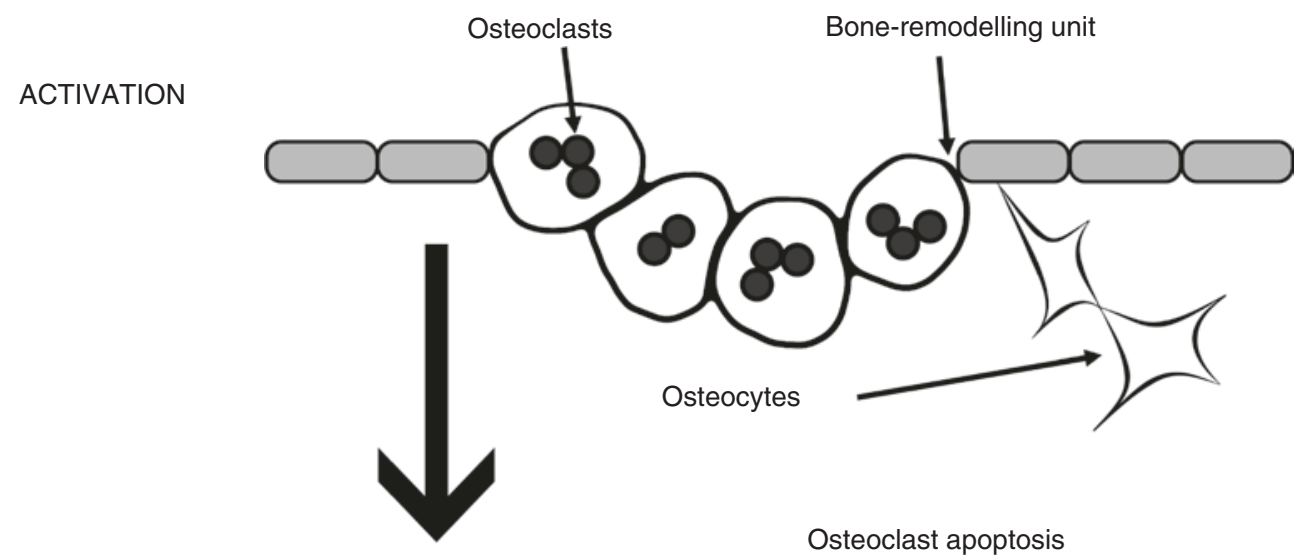

REVERSAL

FORMATION

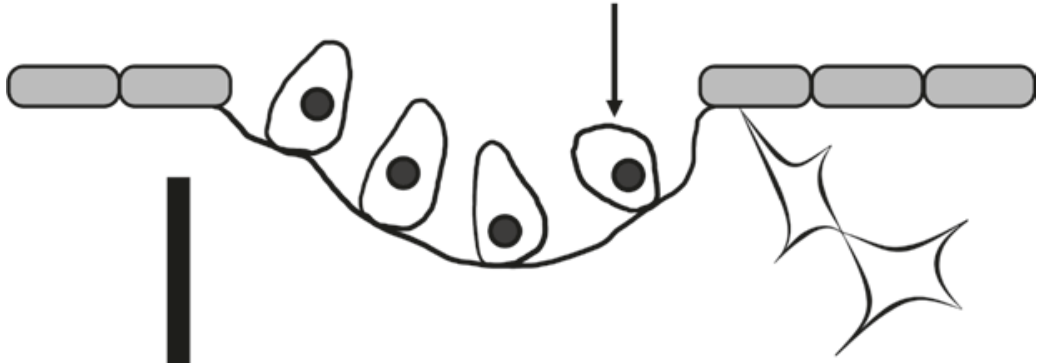

Collagen formation \& mineralization

Osteoblasts

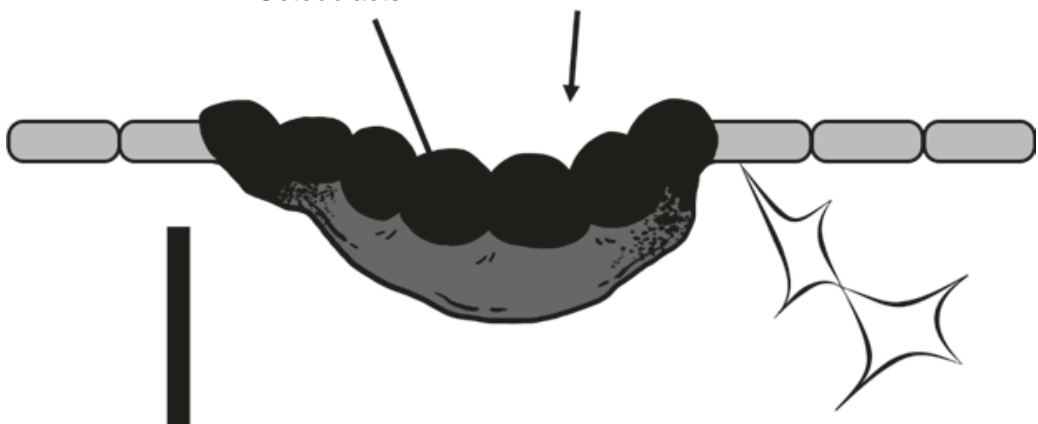

$\checkmark$

RESTING PHASE

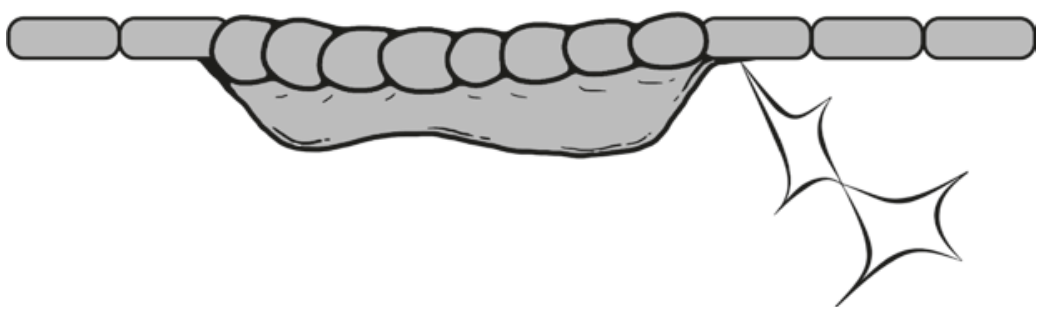

(CAssociation of Oral and Maxillofacial Surgeons of India

These cells release powerful degrading enzymatic proteins that are responsible for the removal of bone minerals.

The extracellular bone matrix consists of about 35\% organic and $65 \%$ inorganic materials. About $90 \%$ of the organic phase is collagen type I fibres, while the remaining
$10 \%$ consists of various non-collagenous proteins. The bone matrix also contains growth factors such as the bone morphogenetic proteins important for bone healing. The inorganic phase of the bone matrix consists of low-crystallinity carbonated hydroxyapatite [9]. 


\subsection{Bone Grafts and Bone Substitutes}

Currently, there are a wide variety of biomaterials that can be used for bony augmentation [10].

Table 19.1 describes the classification of bone grafts [11] (Adapted from Katsuyama H., Jensen S.S. Treatment Options for Sinus Floor Elevation).

Most commonly, bone grafts and bone substitutes are classified according to their source of origin in relation to the intended recipient. Autogenous or autologous bone grafts are obtained from the same individual. Allogeneic bone grafts or allografts are obtained from a genetically distinct individual of the same species. In contrast, xenogeneic bone grafts or xenografts are obtained from a different species than the intended recipient. Alloplastic bone substitutes are synthetically produced materials.

Autogenous bone graft or autograft refers to bone originating from the same patient, and it can be harvested from intra-oral or extra-oral sites. It is preferred to harvest the bone as close to the surgical defect as possible in order to avoid donor-site morbidities. However, of course this decision is dependent on the amount of bone required. For smaller augmentations and guided bone regeneration, bone is commonly harvested from the bone tissue neighbouring the defect site. In this case, donor-site access can be gained from the same incision that is used to access the recipient site. In cases where slightly larger amounts are needed, bone can be harvested from the anterior mandibular ramus or the mandibular symphysis. These are the most common intraoral bone donor sites. Although one may need an additional

Table 19.1 Classification of bone-grafting materials

\begin{tabular}{|c|c|c|c|}
\hline $\begin{array}{l}\text { Autogenous } \\
\text { bone Origin: } \\
\text { the same } \\
\text { person }\end{array}$ & $\begin{array}{l}\text { Allogenic bone } \\
\text { Origin: another } \\
\text { human }\end{array}$ & $\begin{array}{l}\text { Xenogenic } \\
\text { bone Origin: } \\
\text { another species }\end{array}$ & $\begin{array}{l}\text { Alloplastic } \\
\text { bone Origin: } \\
\text { synthetic }\end{array}$ \\
\hline Block graft & Fresh frozen bone & $\begin{array}{l}\text { Bone from } \\
\text { another animal } \\
\text { such as bovine, } \\
\text { porcine }\end{array}$ & $\begin{array}{l}\text { Calcium } \\
\text { phosphates }\end{array}$ \\
\hline \multirow[t]{3}{*}{$\begin{array}{l}\text { Particulate } \\
\text { bone }\end{array}$} & $\begin{array}{l}\text { Freeze-dried bone } \\
\text { allograft }\end{array}$ & $\begin{array}{l}\text { Materials from } \\
\text { corals }\end{array}$ & $\begin{array}{l}\text { Glass } \\
\text { ceramics }\end{array}$ \\
\hline & $\begin{array}{l}\text { Demineralised } \\
\text { freeze-dried bone } \\
\text { allograft }\end{array}$ & $\begin{array}{l}\text { Materials } \\
\text { derived from } \\
\text { calcifying algae }\end{array}$ & Polymers \\
\hline & $\begin{array}{l}\text { Deproteinised } \\
\text { bone allograft }\end{array}$ & & Metals \\
\hline
\end{tabular}

Adapted from Katsuyama H and Jensen S.S: 2011 [11] incision to harvest bone in intra-oral sites, these can be obtained in the same surgical area. When even larger amounts of bone are needed, harvesting from extra-oral sites is needed. The most commonly used donor sites are the iliac bone, the calvarium and the tibia. In most of these cases with the need of an extraoral donor-site harvest, the surgical time as well as hospital stay is often prolonged. A more detailed explanation of different donor sites is provided in the section on onlay bone grafting. In the case of very large bony reconstructions where the defect size is more than 6 centimetres, vascularised bone containing free flaps are used, such as the free fibula flap $[12,13]$. These procedures are commonly carried out for benign and malignant tumours, and are not described in this chapter, but described in detail in the relevant chapter of this textbook.

Allogeneic bone graft or allograft refers to bone originating from another human, either a living donor or following the death of an organ donor. Usually, the allogeneic bone is harvested from the iliac bone or tibia and can be fresh-frozen, freeze-dried or processed as demineralised freeze-dried bone.

Xenogeneic bone substitute or xenograft is bone-substitute material originating from another species. These could be sea algae, corals, equine (originating from horses), porcine (originating from pigs) or most commonly, bovine (originating from cows).

Bone-substitute materials can also be manufactured purely by synthetic means, produced in the laboratory. These are called alloplastic graft materials examples of these are hydroxyapatite, beta-tricalcium phosphate, calcium silicophosphate, bioglasses, polymers, titanium particles or a combination of these.

\section{Box 19.1}

Block bone grafts/Particulate bone grafts: Depending upon the shape and constitution of the bone graft, they can be described as block bone grafts or particulate bone grafts or a combination of these. Bone blocks are large pieces of autogenous bone. Autogenous bone that has been harvested by bone scrapers and chisels is in the form of small chips and is referred to as a particulate graft. Particulate grafts can also be made from block grafts by using special milling machines to break down the block (Fig. 19.4a, b). 

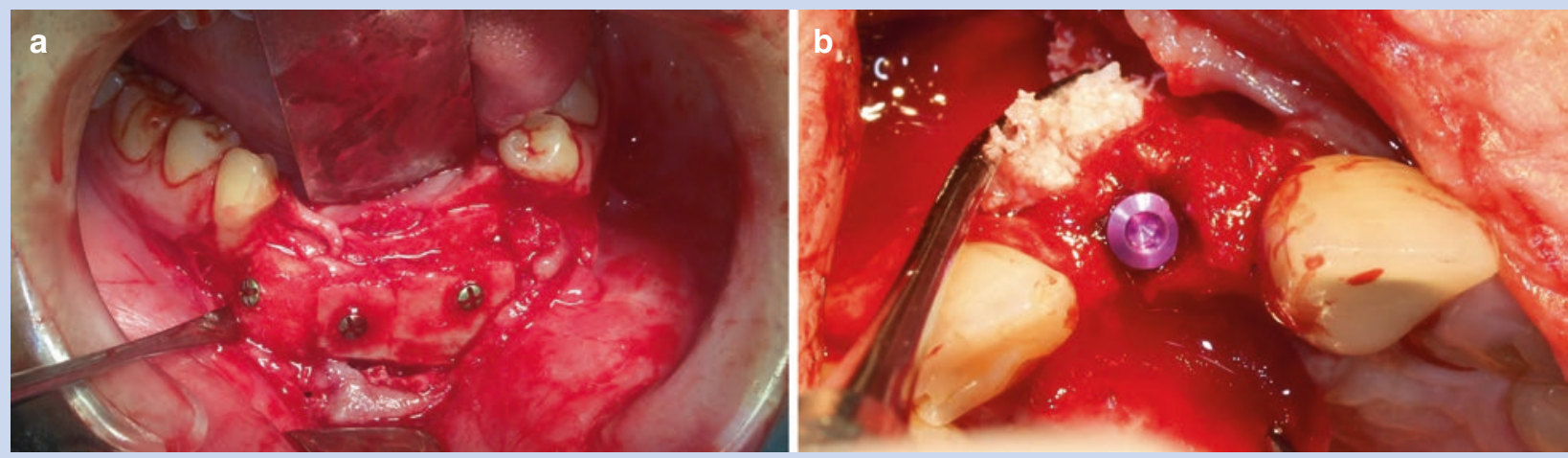

(C)Association of Oral and Maxillofacial Surgeons of India

Fig. 19.4 (a) an example of block bone graft (b) an example of a particulate bone graft

\subsubsection{Classification of Bone Grafts Based on the Mechanism of Action}

Bone grafts can also be described and classified based on the mechanism of action and biological activity into osteogenic, osteoinductive and osteoconductive.

\section{Box 19.2}

Osteogenic grafts provide a source of new bone formation by the osteoblasts that are present in the graft material. At present, this can only be seen in the cases of autogenous bone grafts, where the donor bone is from the same subject and the transplantation procedure has preserved the viability and vitality of osteoblasts in them. Developments using stem cell harvesting may enable development of osteogenic bone grafts without the use of the subject's own bone tissue.

Osteoinduction is defined as the mechanism whereby a bone-substitute material induces bone formation by stimulating undifferentiated mesenchymal cells to turn into osteoblasts, which in turn produce new bone. Many proteins such as bone morphogenetic proteins are being investigated for their osteoinductive properties.

Osteoconduction is the mechanism whereby bone formation is enhanced by providing a scaffold for osteogenic cells that are present in the local environment of the host. Osteoconductive materials form a passive support for cells to migrate and colonise the scaffold and then produce new bone.
In spite of the large number of products available in the market, the gold standard in bone augmentation is autogenous bone. Depending on the indication for grafting and the amount of graft needed, autogenous bone can be used in a particulate form that is used either stand alone, or mixed with a bone-substitute material, used encased in titanium meshes or membranes, as a block graft, or as combination of any of these. Vascularised autogenous bone grafts such as the free fibula flap, the iliac crest and scapula free flap can be used not only as bone flaps but also as composite tissue to reconstruct complete jaws.

Bone augmentation and healing of the graft occurs in the following stages [14]: The surgical intervention gives rise to a haematoma and an acute inflammatory reaction, which is similar to the most cases of tissue trauma. This inflammatory reaction invokes a migration of inflammatory cells into the region, along with osteoblasts and osteoblast precursor cells. In a day's time, proliferation of blood vessels and the beginning of granulation tissue formation occur. This phase is followed by the resorption of the graft by osteoclast precursor cells, and in the case of autogenous bone, this releases bone morphogenetic proteins from the bone matrix, marking the start of the osteoinductive activity. At the same time, osteoblasts from the host bone start to migrate into the grafted region and begin to produce new bone, marking the phenomenon of osteoconduction. The graft is over time incorporated into the regional host bone by undergoing varying degrees of resorption and remodelling.

Although the procedure is largely similar regardless of the origin of the bone graft, the properties of osteoinduction and osteoconduction as well as biocompatibility can vary depending upon the particular bone-substitute material in 
use. Most bone-substitute materials are osteoconductive and vary in the resorption and bone turn-over rates. As a result, certain materials are shown to completely resorb within a period of a few months, whereas certain bone-substitute materials are present after many years.

Autogenous bone is the only type of graft that contributes to bone regeneration via all three mechanisms. A limited number of osteoblasts survive the procedure of grafting and these cells contribute towards osteogenesis; the graft itself provides a scaffold for osteoblasts from the host site to migrate into, facilitating osteoconduction; finally, the growth factors included within the graft matrix and released during graft resorption facilitate osteoinduction. Autogenous bone also has a high rate of resorption.

Allogeneic bone grafts are classified as mineralised and demineralised. Mineralised allografts—such as fresh frozen bone allograft and freeze-dried bone allograft — contribute to bone regeneration primarily through osteoconduction, but they may also possess some potential for osteoinduction. On the other hand, demineralised freeze-dried bone allograft is said to contribute to bone regeneration primarily through osteoinduction, and only secondarily by osteoconduction. However, it should be noted that variations in the processing of allogenic bone grafts from different tissue banks using different methodologies result in a large variation in the composition as well as osteoconductive potential of demineralised freeze-dried bone.

The choice of a commercially available bone-substitute material is most commonly based on the preference of the recipient patient (some patients would not like bone substitutes from an animal source or a cadaveric source), the available product information and documentation of clinical success, product availability, the ease of use and the preference of the clinician.

\subsection{Barrier Membranes}

Barrier membranes are an important component for the success of the GBR procedure. Ideally, the barrier membranes must be non-toxic, biocompatible, cell occlusive with a certain degree of permeability for diffusion of nutrients, permit bonding and ingrowth of connective tissue during healing, should be of sufficient rigidity to maintain the space created and not collapse into the defect, it should be easy to handle clinically and should be able to be trimmed to tailor the material as per the size of the defect [15].

Although traditionally many materials such as PTFE had been developed as membranes, currently most membranes being used are made up of collagen (type I, type III or a com- bination of these) [16]. These collagen membranes are derived from porcine or bovine sources [17]. Collagen membranes resorb as a result of enzymatic action of macrophages and polymorphonuclear leukocytes. Some manufacturers cross-link collagen membranes with glutaraldehyde to reduce the rate of membrane resorption, thereby prolonging the barrier function. However, crosslinking with glutaraldehyde can result in cytotoxic residues in the membrane following its manufacture. Resorbable membranes have a less likelihood to cause early membrane exposure, and that additionally due to the property of being resorbable, they do not need to be removed at a second surgical procedure.

Clinically, the main advantage of resorbable membranes is their decreased susceptibility to infective complication. If premature membrane exposure occurs, secondary soft tissue healing takes place within 4 weeks, and the bone-regenerative outcome remains favourable. Collagen membranes are also easier to handle clinically and adapt well to the surgical site once they are wet with blood or saline. Significantly, the membranes do not need to be removed via a second surgical procedure because they biodegrade. The main disadvantage is that non-cross-linked collagen membranes collapse easily because they do not have space-maintaining properties.

When a membrane with insufficient stiffness and rigidity is used in larger defects, there is a high likelihood of membrane collapse. Collapse of the membrane would lead to a situation where there would be no space for guided bone regeneration. Hence, clinically this problem is solved by using a bone graft or a bone-substitute material that fills the bone defect and provides support to the membrane. Other methods to support the barrier membranes include the incorporation of bendable titanium frameworks into PTFE material, tenting screws to support the membrane and titanium mesh that can be shaped and adapted to the site. However, these procedures would require an additional surgical procedure to remove the hardware [18].

\subsubsection{Success Parameters of Autogenous Bone Graft Healing}

The success of bone augmentation is dependent on the ability of the augmented bone to support an implant fixture at the desired position. However, in biological terms the extent of graft incorporation, turnover, replacement, the volume stability and the time taken for healing are dependent on many factors such as surgical factors, patient-related factors and material-related factors. It has been shown in multiple systematic reviews and innumerable clinical studies that there is no one single superior bone-substitute material [14]. Bone 
augmentation, although having well-documented success rates, depends upon surgical as well as patient-related factors. Amongst the surgeon-related factors are the training of the surgeon, their surgical expertise, the adherence to protocol and treatment of the graft material as well as the recipient site, adequate fixation of the graft to prevent movement between the graft and recipient bone and so on.

Patient-related factors that contribute to healing include underlying systemic diseases such as immunodeficiency, diabetes; local factors and habits such as oral hygiene and oral health, smoking and use of tobacco and defect-related factors such as the size of the defect and the morphology of the defect. It should be noted that smaller augmentations in a three-walled defect are more successful than large only vertical bone augmentation.

Regarding the influence of the grafted material used, it has been shown that particulated autogenous bone has the advantage of relatively fast incorporation in comparison with autogenous bone blocks [19]. However, particulate bone lacks structural stability and is prone to undergo unpredictable and extensive resorption. In contrast, autogenous bone blocks provide structural stability leading to better dimensional stability. However, block grafting requires a longer healing period of at least 6 months with about $50 \%$ (half the initial augmented volume) resorption at the end of the healing period.

Regarding the influence of bone-substitute materials, there exists a large variation in the physicochemical characteristics of the various bone substitutes available in the market, including their composition, particle size and form and surface properties. These differences can result in varying outcomes following augmentation.

Differences in the amount of new bone formation can be due to true differences in the osteoconductive potential of the biomaterial, but may also partly be explained by differences in resorption capacity amongst the various bone substitutes, which in turn determine the space available for new bone tissue formation within the defect site. For example, betatricalcium phosphate is replaced rather quickly, while sintered bovine bone is resistant to resorption and will be present in the augmented site for decades.

\subsection{Commonly Carried Out Augmentation Procedures}

Currently implantology has developed rapidly. Newer techniques and materials are constantly being introduced. The choice of procedure depends mainly upon the surgeon. Based upon the amount of bone augmentation required, the commonly carried out procedures are:
GBR (guided bone regeneration)

Onlay bone grafting

Sinus floor elevation

These procedures are described in detail below.

\subsection{Guided Bone Regeneration}

Guided bone regeneration is a bone-augmentation technique that uses the principle of space maintenance within a bony defect with the use of a barrier membrane. The barrier membrane excludes rapidly proliferating epithelial cells and connective tissue fibroblasts, thus allowing the ingrowth of slower-growing bone cells and blood vessels into the blood clot within the defect.

The concept of guided bone regeneration was introduced and developed first by Nyman and colleagues; Dahlin and colleagues in the early 1980s [20, 21]. Multiple animal studies showed that bone defects protected by a barrier membrane, which did not permit ingress of cells, had increased bone fill as compared to defects that were not protected by a barrier membrane. Although the technique was first described for periodontal defects around natural teeth, later studies showed that GBR was also predictable in forming bone around implant defects.

Clinically, GBR is performed by raising a mucoperiosteal flap and exposing the bony defect. This defect is filled with a bone substitute and then covered with a barrier membrane. The bone defect with the bone substitute is filled with blood, which later clots and forms a haematoma. Over a period of time, the haematoma is ingressed by blood vessels and osteoprogenitor cells from the surrounding environment, which over a period of time forms bone tissue by resorbing the existing substitute and replacing it or growing into the substitute that acts as a scaffold. The barrier membrane prevents the ingress of fast proliferating fibroblasts and epithelial cells into the bone defect, thereby creating a space for bone to form and mature.

However, GBR does not produce similar successful outcomes in all morphology of defects [22]. The more the bone walls the defect contains, the better the bone fill following GBR. Bone walls provide an exposed surface of bonerecruiting cells. With more bone walls, an increased number of osteogenic cells are able to migrate along newly proliferating blood vessels into the haematoma in the defect. When two or three walls are present, the blood clot is less likely to be moved and better protected during the healing phase.

Guided bone regeneration can be applied for the correction of minor requirements of bone augmentation. They are documented to be successful in the following clinical situations: 


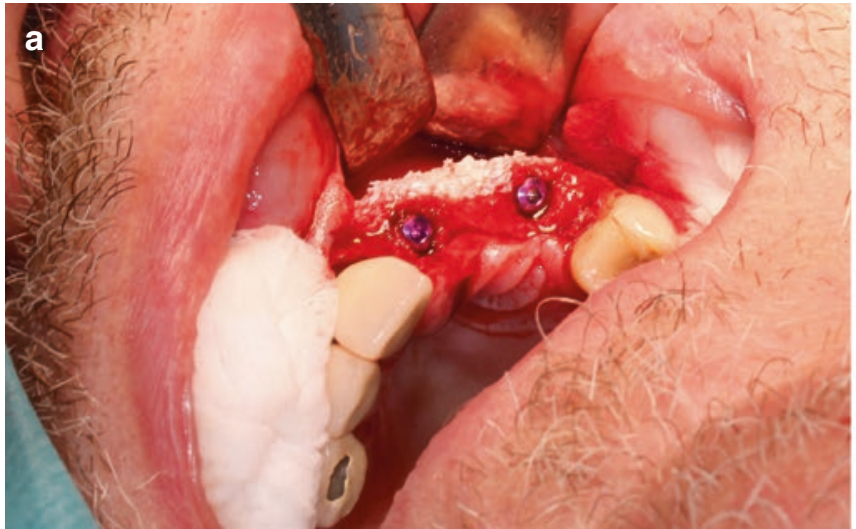

CAssociation of Oral and Maxillofacial Surgeons of India

Fig. 19.5 (a, b) Shows a clinical case of GBR for a 2 walled defect

1. Used to augment 2- or 3-walled crestal bone defects when implants are placed into extraction sites.

2. Used for augmenting bone when there is an apical fenestration following implant placement.

3. GBR can be used for ridge preservation.

4. GBR can be performed as a combination to other larger augmentation procedures.

5. GBR can be used for contour augmentation to increase the thickness of the facial bone for aesthetic reasons.

\subsubsection{Augmentation of 2 and 3 Walled Defects}

Guided bone regeneration can be successfully used in cases with crestal bone defects that are seen while placement of implants into extraction sites. If an implant can be placed with sufficient primary stability and results in a 2 or 3 walled defect, or if the defect is well contained in the bony envelope, GBR can be successfully performed at the time of implant placement. If these factors are not present, the augmentation must be performed prior to implant placement as a staged approach. In these cases, depending on the size and morphology of the defect, augmentation can be performed either by GBR, or by other augmentation methods described later in the chapter.

Figure $19.5 \mathrm{a}, \mathrm{b}$ shows a case of GBR augmentation of 2 walled defect.

\subsubsection{For Augmenting Apical Fenestrations}

Often when implants are placed in the correct prosthetic position, with the correct angulation in order to provide screw retained restorations, the ideal angulation of placement would result in an apical fenestration, with the apical

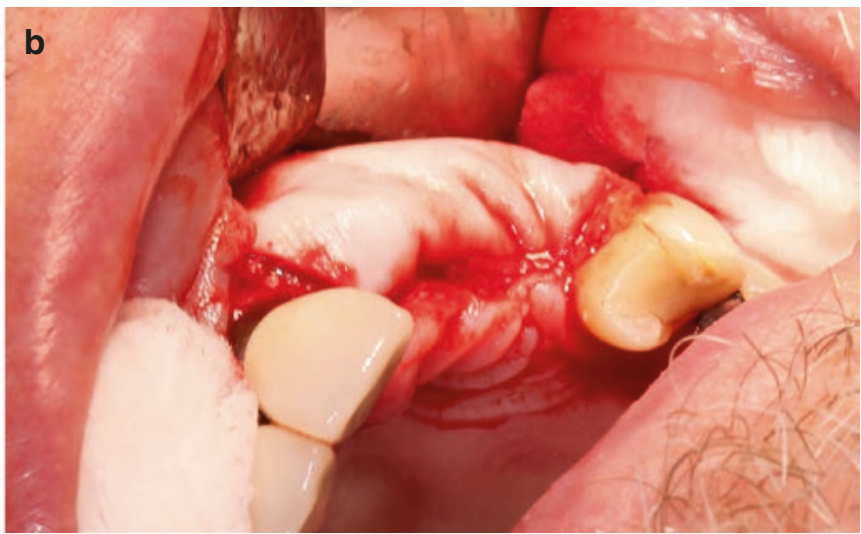

part of the implant threads being exposed. In these situations, the fenestration defects can be covered by using particulate bone/substitute material, covered with a membrane, as per the principles of GBR.

\subsubsection{GBR for Ridge Preservation}

During preoperative assessment and after extraction of a hopeless tooth that is planned to be restored with an implant, it is essential to inspect the shape of the resulting socket. In many situations, either due to trauma or chronic infection, the facial bone wall is missing. In these cases, it is important to augment the ridge/preserve the ridge at the time of tooth extraction. GBR can be well employed for this procedure known as ridge preservation/alveolar ridge preservation. In cases of acute infection in the sockets, ridge preservation can be carried out at a later stage after the infection has subsided.

\subsubsection{GBR in Combination with Other Larger Augmentation Procedures}

In the cases of localised prolonged ridge atrophy, GBR can be combined with other methods of augmentation such as with block grafts or ridge split techniques. In the cases of prolonged ridge atrophy affecting a complete segment of the jaws, the bone defects would often contain a single wall or two walls with a requirement for larger volumes of grafting. GBR alone will not provide a sufficient amount of bone augmentation. In these situations, it is advisable to augment using block grafting, and in addition use particulate bone graft around the blocks and protect the augmented particulate material with a membrane. Implant placement can then be carried out after a period of around 6 months. 


\subsubsection{GBR for Contour Augmentation}

One successful method of placing implants is following 4-8 weeks of healing. In this situation, in contrast to immediate implant placement, soft tissue healing would have taken place, thereby permitting the clinician with better quality of soft tissues while placing implants. However, in this scenario, especially in the aesthetic zone, the resorption of the facial bone would produce crater-like bone defects. GBR can be done in these situations, to over correct the lost facial bone as well as provide bulk to the region of implant placement. This procedure is also called 'contour augmentation' [23]. By doing this procedure, the buccal bone wall is intentionally overbulked so as to provide long-term stable aesthetic results as shown by multiple studies [24].

\subsection{Onlay Bone Grafting}

Onlay bone grafting is a predictable procedure carried out for the correction of cases with severe ridge resorption, either horizontally or vertically [25]. Autogenous bone grafts are the most documented and commonly used donor bone, although recently other allogenic and xenogenic materials are being clinically investigated. For augmentation of severe ridge defects (less than 2 walls and require more than $3 \mathrm{~mm}$ of augmentation), augmentation utilising autogenous bone blocks results in increased success rates as compared to guided bone regeneration alone. However, irrespective of the augmentation technique, vertical-ridge augmentation is less predictable as compared to horizontal-ridge augmentation [26].

Donor sites for autogenous onlay bone augmentation may be intra-oral or extra-oral. Most common intra-oral donor sites are the mandibular symphysis and the ramus of the mandible. Most common extra-oral donor sites for harvesting non-vascularised bone grafts are the iliac crest, the calvarium and the tibial bone. Most common vascularised bone containing free flap donor sites are the free fibula flap, the DCIA-free flap and scapula-free flap.

Once the bone graft is harvested, they should be trimmed and shaped to fit into the recipient site defect, stabilisation with osteosynthesis screws followed by adequate soft tissue mobilisation and tension-free primary closure of the grafted site. It is advisable to over-augment the defect in order to compensate for the eventual resorption. A mixture of particulate bone, slow-resorbing xenografts either alone or in combination is used to fill up the area between a corticocancellous block and the recipient site. The augmented material may be protected with a barrier membrane prior to being enveloped by the soft-tissue closure.

\subsubsection{Harvesting Bone from the Donor Site}

\subsubsection{Mandibular Ramus as the Donor Site}

The outer cortical plate of the ascending ramus of the mandible is a popular choice for the harvest of intra-oral bone. This is probably because many oral and maxillofacial surgeons are well accustomed to the approach to the ramus during routine mandibular third molar surgeries or routine orthognathic surgeries. (Fig. 19.6a, b, c shows harvest of bone from the mandibular ramus).

The incision starts with a crevicular incision around the last standing molar teeth and continues along the ridge curving buccally upwards along the external oblique ridge. After elevation of the mucoperiosteal flap, and gaining adequate access to the anterior and lateral border of the ascending ramus of the mandible and the angle region, bone harvesting can begin. Usually, a block graft of approximately $30 \mathrm{~mm} \times 15 \mathrm{~mm}$ can be harvested. The block thickness depends on the thickness of the lateral cortical bone plate of the ascending ramus and can vary from about 3 to $4 \mathrm{~mm}$. The outline of the graft is usually made with two parallel anterior and posterior osteotomy cuts of about $3 \mathrm{~mm}$ in depth, on the lateral surface of the ramus of the mandible till the cortical bone is penetrated completely. Round bur points can also be made outlining the bone graft prior to making parallel cuts. Use of piezosurgery is advantageous in the cases of bone grafting. The two horizontal osteotomies are then joined by the sagittal bone cut superiorly. This cut corresponds to the thickness of the cortical bone. Once the sagittal bone cut is complete, the bone graft can be gently fractured and mobilised by the introduction of an osteotome or a periosteal elevator. Some surgeons prefer to make a cortical cut at the inferior end of the bone block prior to introducing the periosteal elevator to prevent unfavourable fractures of the block graft. After bone harvest, the surgical area is irrigated well and a haemostatic agent is applied if necessary and the wound is closed in layers. Some surgeons prefer to insert a glove drain that will be removed after 3 days.

\subsubsection{Chin (Anterior Mandible) as the Donor Site}

The chin is also a popular donor site, predominantly because of the ease of access to the donor site. However, block grafts from the chin have shown an increased risk towards complications, especially neurosensory and vascularity disturbances to the mandibular incisors. Bone grafts of $50 \mathrm{~mm}$ in length and about $8 \mathrm{~mm}$ of width can be harvested. The cortical portion of the anterior mandible is thicker (around 3-11 mm) and hence the chin would provide a thicker area of bone and would be a choice for thick bone grafts. It is also popular to harvest bone grafts from the chin using trephine 

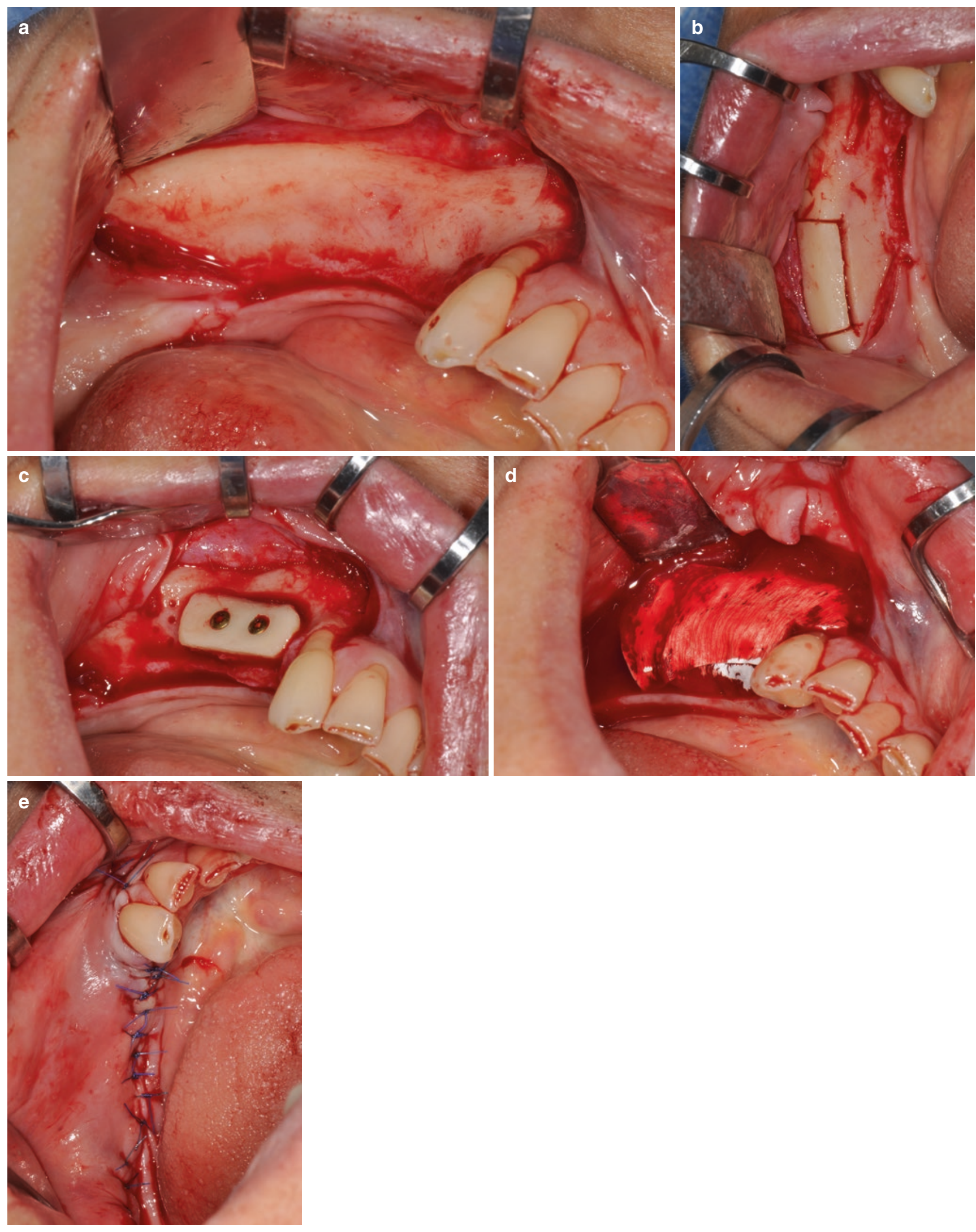

CAssociation of Oral and Maxillofacial Surgeons of India

Fig. 19.6 Shows harvest of bone from the mandibular ramus. (Picture courtesy PD Dr.med.dent. Simone Janner, Department of Oral Surgery and Stomatology, University of Bern, Switzerland). (a) Incision for access to ascending ramus. (b) Outline of the osteotomy. (c) Graft fixed at recipient site. (d) Coverage with membrane following additional particulate augmentation. (e) Closure 

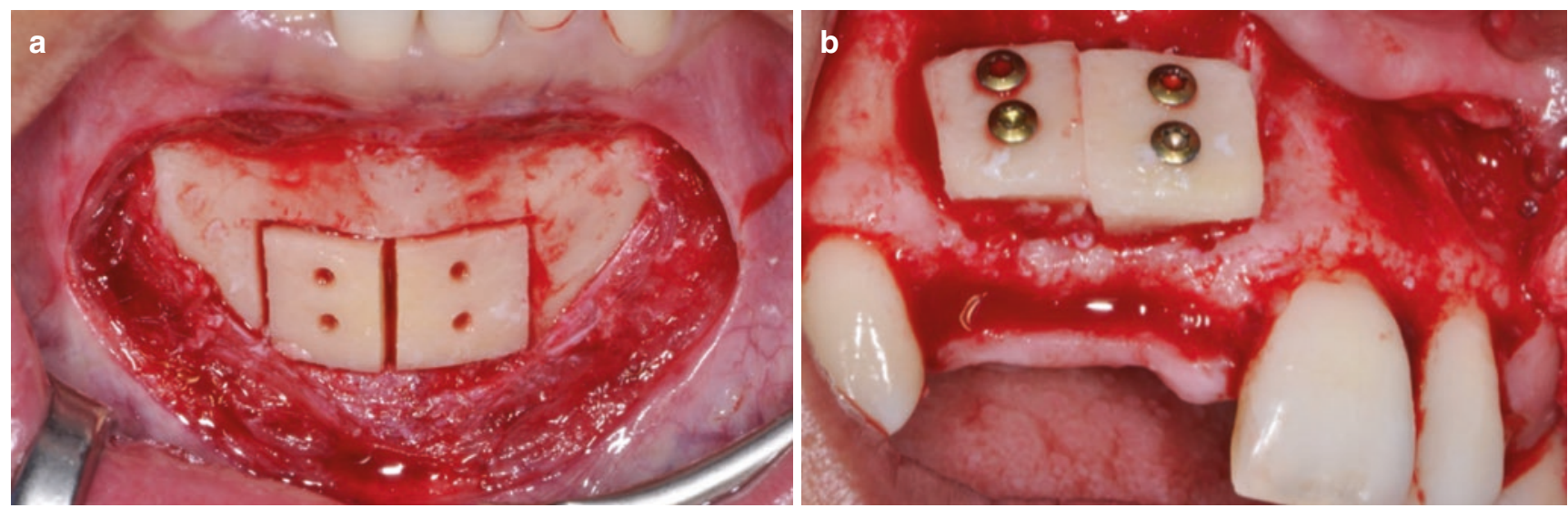

CAssociation of Oral and Maxillofacial Surgeons of India

Fig. 19.7 (a, b) Shows harvest of bone from mandibular symphysis. (Picture courtesy PD Dr.med.dent. Simone Janner, Department of Oral Surgery and Stomatology, University of Bern, Switzerland). (a) Harvest of bone from symphysis. (b) Graft secured at recipient site

burs of varying diameters (7-12 $\mathrm{mm})$, and using upto 4 trephine harvests. (Fig. 19.7a and b shows harvest of bone from mandibular symphysis).

The access to the chin is by a standard vestibular incision from one canine to another with approximately $15 \mathrm{~mm}$ away from the mucogingival margin. Once the mucosa is incised, the underlying mentalis muscle is seen, which is incised obliquely to reach the symphysis of the mandible. Full thickness flap is elevated and the donor site inspected. For harvesting larger grafts, it is advisable to expose both the mental foraminae. Once the donor site is exposed as per the requirement, the boundaries of bone harvesting are carefully noted. An intact area of $5 \mathrm{~mm}$ must be preserved inferior to the root ends of the anterior teeth and $5 \mathrm{~mm}$ above the lower border of the mandible. Bone graft can be outlined within these borders, either using piezo surgical device or round burs or fissure burs or most popularly, trephine burs. After the outline of the bone graft is made, osteotomy of the cortical portion is done and connected. An osteotome or a periosteal elevator is then gently introduced to tease out the graft.

After harvesting of the bone graft, haemostasis is achieved and the wound closed in layers. It is important to close the periosteal layer and approximate the mentalis muscle prior to mucosal closure. A compressive chin dressing is provided to apply pressure to the donor-site region.

\subsubsection{Iliac Crest as the Donor Site}

Iliac bone provides a large quantity of bone and is the preferred donor site for large bone augmentation as it is an excellent source for cortical and cancellous as well as corticocancellous bone. Both the anterior and posterior iliac crest can be used as a donor site. Anterior iliac crest grafts are associated with higher complication rates of sensory disturbances, gait problems and untoward ilium fracture. Posterior crest grafts are associated with lesser complications but increased post-operative pain. Additionally, posterior crest grafts require the patient to be repositioned and hence many surgeons prefer the anterior iliac crest. (Fig. 19.8a, b, c shows a case of harvest of bone from iliac crest).

The harvest of bone from the anterior iliac crest is generally performed with the patient under general anaesthesia. The patient is positioned supine and the side of the pelvis to be operated on is raised by placing surgical towels or sandbag towels underneath the hip. The skin over the crest is made taut by placing a fist above the iliac crest and only pushing the abdominal wall medially. The skin incision is made generally about $2 \mathrm{~cm}$ larger than the intended length of the bone harvest, running parallel to the iliac crest, so that after relaxation of the taut skin, it lies lateral to the iliac crest thereby avoiding mechanical irritation of the scar. After skin is incised, blunt dissection of the subcutaneous tissue is made until the periosteum of the iliac crest is seen. Bleeding should be controlled during dissection. The periosteum of the iliac crest is incised and the periosteal layer with the attached muscle is elevated and reflected medially. The iliac fossa is dissected to the desired depth. Care should be taken to avoid injury to the lateral femoral cutaneous nerve. Bone can be harvested using an oscillating saw or a piezosurgical device as per the preference of the surgeon by splitting the outer cortex of the iliac crest and transverse bone cuts. The two transverse cuts are then joined by a cortical osteotomy at the inner table paralleling the crestal cut. An osteotome is used to gently fracture the bone graft. This results in a cortico cancellous bone graft. Additional cancellous bone 

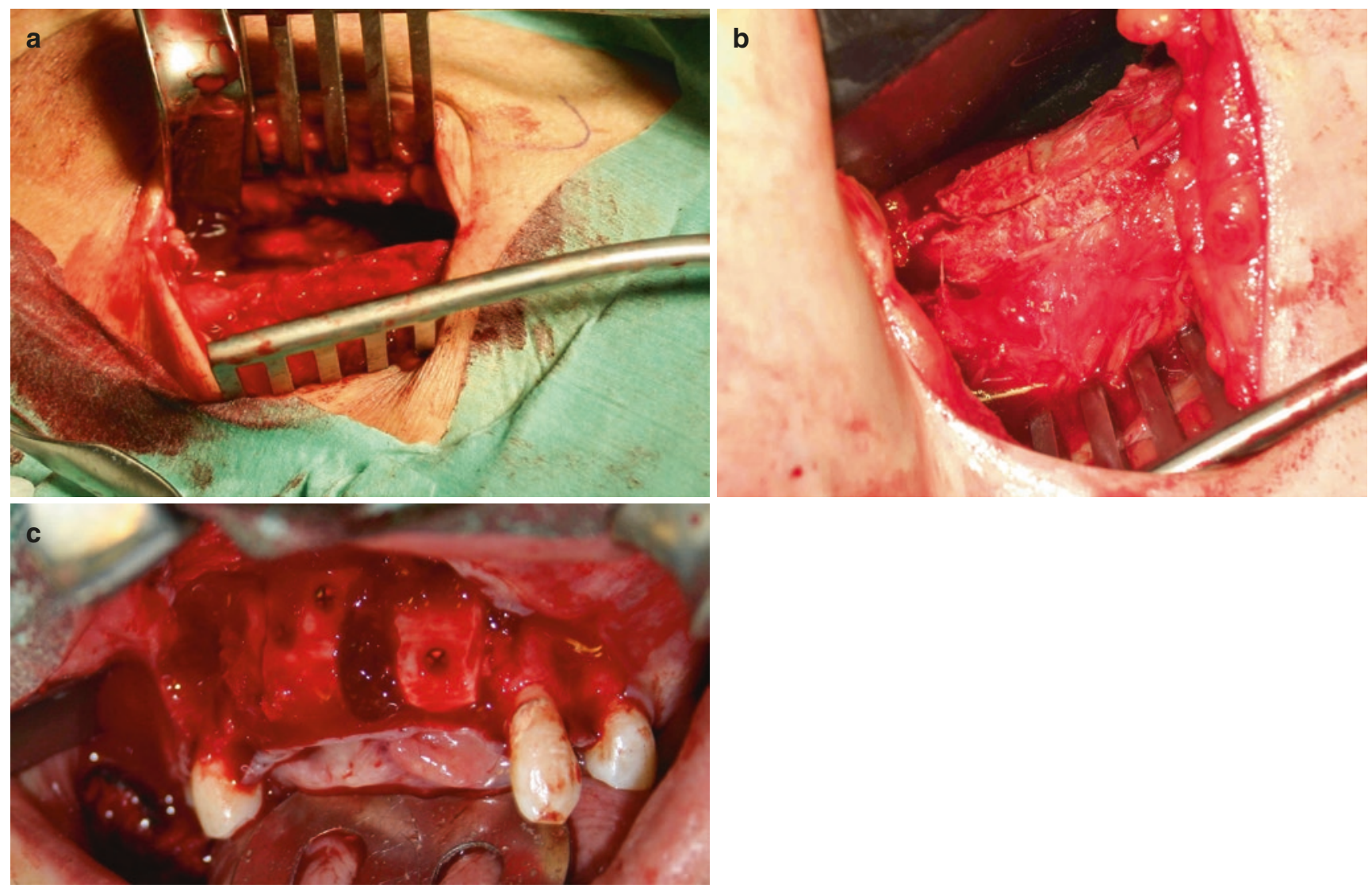

CAssociation of Oral and Maxillofacial Surgeons of India

Fig. 19.8 (a, b, c ) Shows a case of harvest of bone from iliac crest used to augment anterior maxilla. (a) Shows the exposure of the anterior iliac crest for bone harvesting. (b) Shows the osteotomy of iliac crest for harvest of bone. (c) Shows the harvested bone fixed at recipient site

can be taken with a large curette if needed. The wound is meticulously closed in layers and a pressure dressing is applied.

\subsubsection{Calvarium as a Donor Site}

Calvarium is a good source of cortical bone graft due to its high density and is opined by some surgeons as being the most resistant to resorption [27]. The location of the donor site is at the parietal bone lateral to the sagittal suture. The bone has distinct outer and inner table at this region separated by a diploic layer. A typical situation where calvarial bone grafts are harvested is in the cases of residual deformities following trauma, where a bicoronal flap and exposure of the parietal bone are already planned. (Fig. 19.9a, b, c shows a case of calvarial bone harvest used for bone augmentation of the anterior mandible).

The harvest is performed under general anaesthesia and the parietal bone exposed as part of the bicoronal flap. The outline of the bone graft is first made with round burs and then joined with straight fissure burs. The outline of the graft is broadened to permit placement of a chisel that would fracture the outer cortical plate at the diploic space. Haemostasis is achieved and the wound is closed.

\subsubsection{Recipient Site Preparation and Completion of the Procedure}

The preparation of the recipient site is done by a crestal incision with adequate releasing incisions as required. The surface of the bone is cleared of soft tissue and the cortical bone plate of the recipient site is perforated with a small round bur to produce bleeding and gain access to the cancellous part of the recipient bone. The harvested bone is then placed onto the recipient site and fixed with osteosynthesis screws. Some surgeons prefer to use lag screws for additional compression. The spaces between the block graft and recipient bone can be filled with particulate bone, especially at the borders. A resorbable membrane may be used to cover the augmentation. Adequate soft tissue release must be performed prior to 

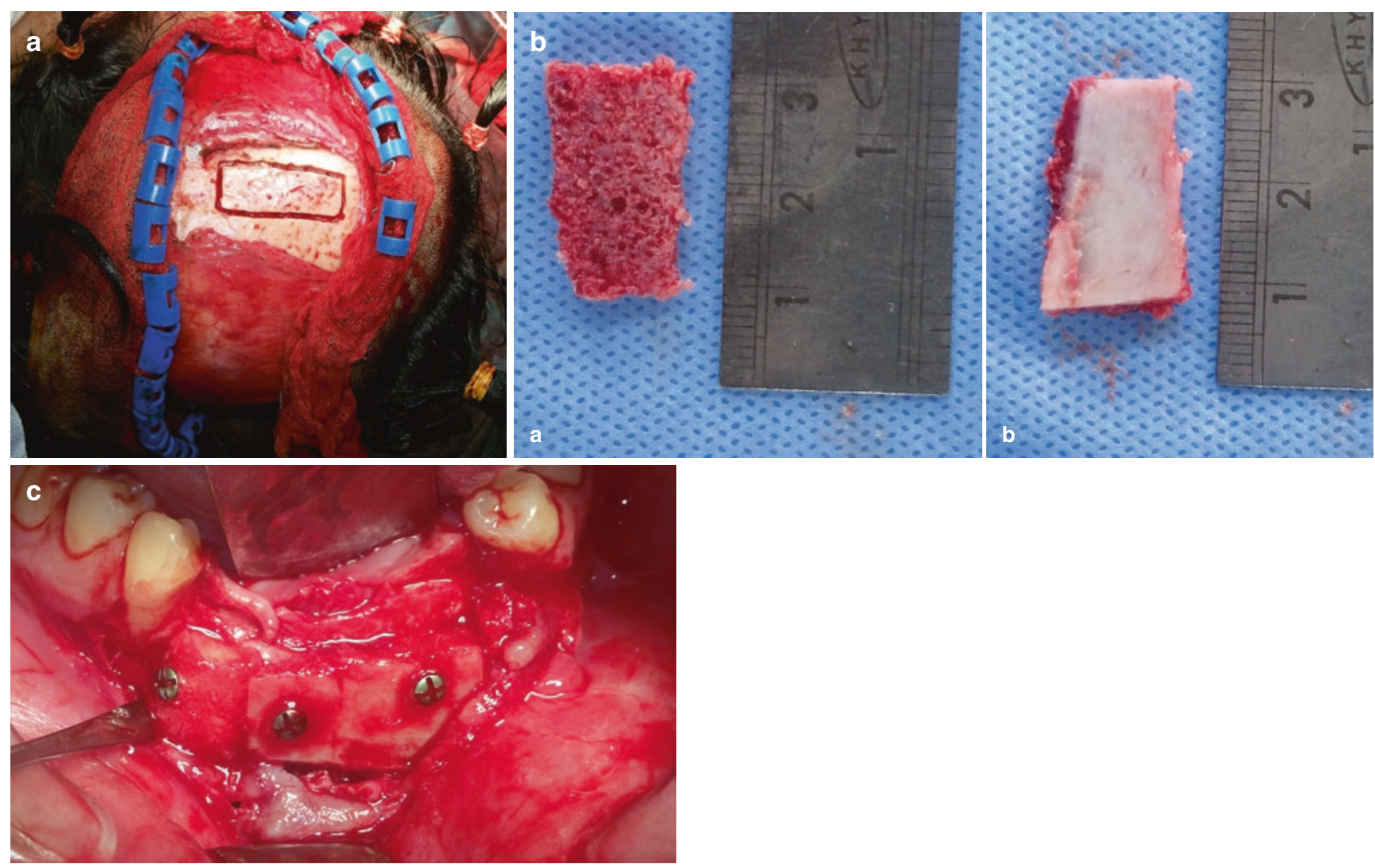

CAssociation of Oral and Maxillofacial Surgeons of India

Fig. 19.9 (a, b, c) shows a case of calvarial bone harvest used for bone augmentation of the anterior mandible. (a) Shows the exposure of the donor site with the outline of bone to be harvested. (ba) Shows the cancellous side of the harvested bone. (bb) Shows the cortical side of the harvested bone. (c) Shows the harvested bone further shaped and fixed at the recipient site closure, so as to provide a tension-free watertight closure. Onlay grafts are usually left to heal for at least 6 months, after which implant placement can be carried out as another surgical procedure.

Another variation of onlay bone grafting is to use the cortical shell technique, where a thin cortical shell of bone is harvested and cancellous bone marrow placed in between the cortical shell and the recipient bone wall.

Other methods of bone augmentation include ridge split for lateral augmentation, alveolar distraction osteogenesis for vertical augmentation, interpositional bone grafting and free flap reconstruction of extremely resorbed ridges [28, 29]. These procedures will not be described in detail as they are not the most commonly carried out procedures.

\subsection{Sinus Floor Elevation}

Sinus floor elevation, also known as sinus augmentation or sinus lift is a bone-augmentation procedure to gain an increased bone volume to support in the maxillary sinus following sinus pneumatisation. The bone augmentation is done to provide an adequate quantity of bone that would permit dental rehabilitation with implants.

Maxillary sinus floor elevation can be performed by either as a transcrestal technique (also known as indirect sinus floor elevation) or a lateral window technique (also known as direct sinus floor elevation).

Irrespective of the individual techniques, the principle is to elevate the Schneiderian membrane and to create space for bone to fill up between the elevated Schneiderian membrane and residual maxillary bone. Although most clinician commonly use bone grafts to fill the space between the membrane and the floor, it has also been shown that bone fill occurs irrespective of using a bone substitute or leaving the elevated area to be occupied by a blood clot that eventually forms bone [30-32]. (Fig. 19.10a, b, c, d shows a clinical case of sinus floor elevation with blood clot and no additional biomaterial).

The maxillary sinus is a pyramidal-shaped cavity in the posterior region of each of the maxillary bones. The base of this pyramid is the lateral nasal wall and the tip of the pyramid is within the zygomatic buttress. The infraorbital floor, the posterior maxillary wall and the alveolar process form the walls of the pyramid. The maxillary sinus communicates 

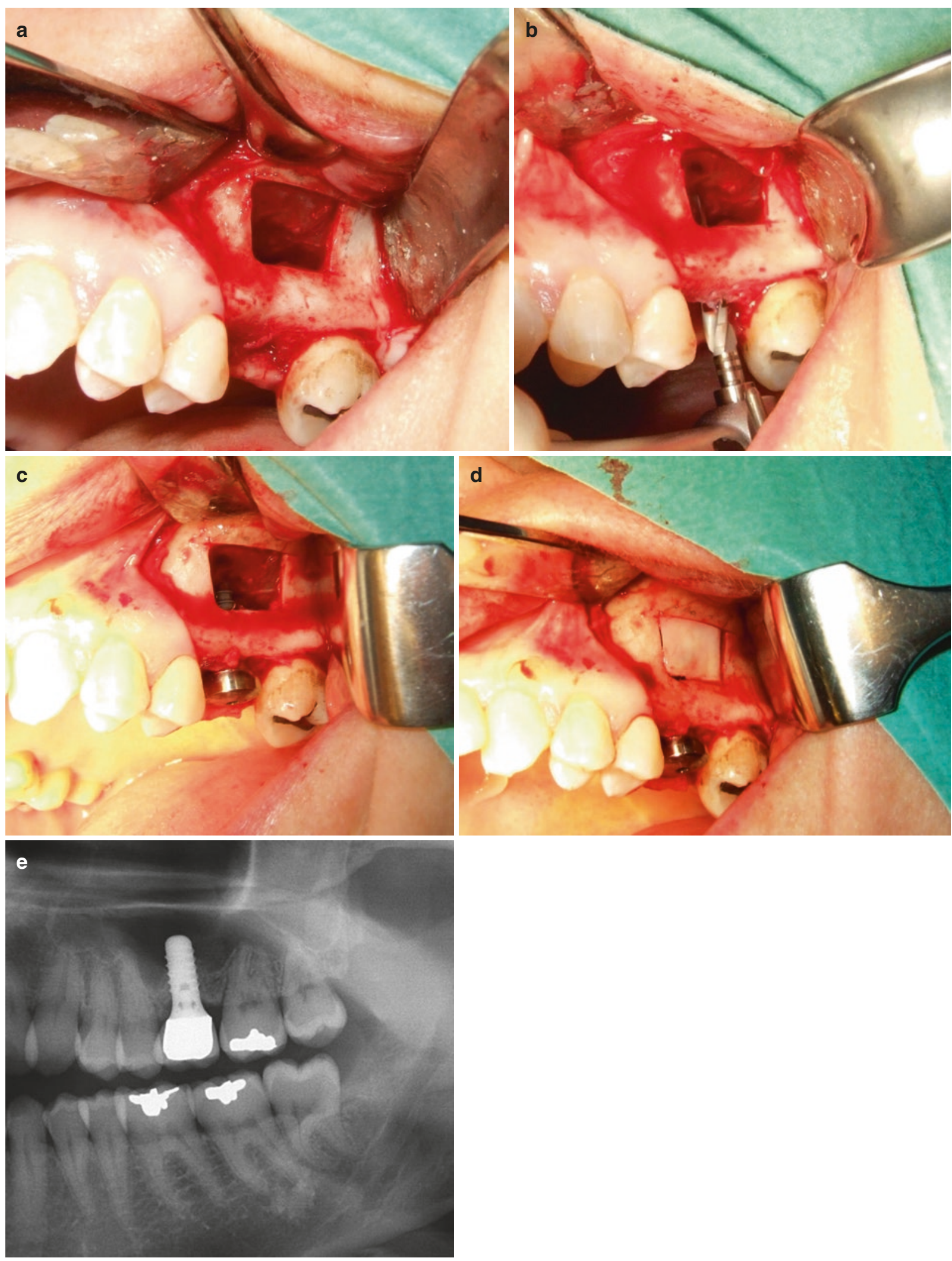

CAssociation of Oral and Maxillofacial Surgeons of India

Fig. $19.10(\mathbf{a}, \mathbf{b}, \mathbf{c}, \mathbf{d}, \mathbf{e})$ shows a clinical case of sinus floor elevation with blood clot and no additional biomaterial. (a) Preparation of lateral window and elevation of the sinus membrane. (b) Implant osteotomy taking care to protect the membrane. (c) Implant placed (note the space between the implant and membrane that will eventually fill with blood clot). (d) Closure of the lateral window. (e) Long-term follow-up radiograph showing successful implant placement and restoration 
to the lateral nasal wall through the semilunar hiatus at the posterosuperior aspect below the medial nasal concha. At birth, the maxillary sinus is very small and underdeveloped. As the permanent teeth begin to erupt, the maxillary sinus increases in size and continues to grow along with age. The sinus floor (the alveolar bone) is concave in shape with the lowest dip corresponding to the maxillary molar region. However, after the loss of maxillary posterior teeth, the sinus usually dips into this region. Over a period of time due to the increasing pneumatisation of the sinus, the sinus may surround the roots of the maxillary posterior teeth. In the case of the loss of maxillary posterior teeth, the maxillary sinus expands thinning the floor of the alveolar process that may result in a thin shell of bone. In many situations, this expansion of the maxillary sinus leaves an inadequate amount of bone to support successful implant placement. In these situations, maxillary sinus floor elevation is the procedure of choice to augment bone. However, it is also important to bear in mind that alveolar bone resorption may give rise to vertical and horizontal deficiencies in the posterior maxillary sinus. In prolonged cases, this might give rise to a situation where along with sinus floor elevation, it would also be necessary to augment bone both horizontally and vertically by onlay bone augmentation.

The morphology of the maxillary sinus floor can vary. Maxillary sinus floors are often irregular corresponding to the elevations and depressions of the teeth roots. The floor of the sinus also may be divided by septae. Some maxillary floors are broad and flat whereas others may be irregular and narrow. The lateral wall of the maxillary sinus can also vary in thickness, from being paper thin to being about $3 \mathrm{~mm}$ in thickness. The thicker the lateral wall, the more difficult would be the lateral sinus floor-augmentation procedure.

The blood supply of the maxillary sinus arises from the branches of the maxillary artery namely: the posterosuperior alveolar artery and the greater palatine artery as well as the infraorbital artery. Care must be taken to look out for the posterosuperior alveolar artery that may be encountered while preparation of the lateral sinus floor augmentation, although it is unlikely to cause excessive bleeding.

As required for all surgical procedures, a thorough preoperative assessment must be carried out prior to sinus floor elevation. Acute sinusitis, oro-antral communications, chronic periodontitis and poor oral hygiene pose a high risk for sinus floor elevation. Moderate risk factors include smoking, chronic sinusitis and extremely poor bone density, amongst others.

\subsubsection{Classification and Treatment Options for the Posterior Edentulous Maxilla}

According to the International Team for Implantology, the edentulous posterior maxilla can be classified into 4 types [11]:
Group 1: where there is an insufficient sub-antral bone height to place implants, however with an adequate width of the alveolar ridge with acceptable vertical and horizontal interarch relations. These cases can be treated with a sinus floor elevation procedure alone.

Group 2: where there is an insufficient subantral bone height, and an inadequate width of the alveolar ridge with acceptable vertical interarch relation. In these cases, sinus floor elevation should be performed along with horizontalbone augmentation.

Group 3: where there exists an insufficient subantral bone height, and an adequate width of alveolar ridge with acceptable horizontal interarch relations but with unfavourable vertical interarch relationship. In these cases, sinus floor augmentation should be performed along with vertical-ridge augmentation.

Group 4: There exists insufficient subantral bone height, and unfavourable interarch relations in addition to advanced horizontal and vertical crestal resorption. These cases must be treated with sinus floor elevation along with horizontal and vertical-ridge augmentation.

Misch 1987 [33] classified the edentulous posterior maxilla based on the amount of subantral bone available into:

SA1: more than $12 \mathrm{~mm}$ of the subantral bone height.

SA2: 0-2 mm less than the ideal bone height (10-12 $\mathrm{mm}$ ).

SA3: 5-10 $\mathrm{mm}$ of the subantral bone height.

SA4: less than $5 \mathrm{~mm}$ subantral bone height.

\subsubsection{Decision-Making: Lateral Versus Transcrestal Technique}

Transcrestal technique avoids the use of a large surgical flap and an osteotomy for a lateral window and hence is much reduced in invasiveness and decreased post-operative morbidity to the patient. However, the transcrestal technique can predictively increase bone height to about 4-5 $\mathrm{mm}$ and, therefore, cannot be used for severely atrophic cases. Additionally, in situations where the sinus floor is not uniform (or at oblique angles), there is an increased tendency to perforate the sinus mucosa. In such cases, it is preferable to perform lateral sinus floor elevation. It must be remembered that the transcrestal technique is in essence a blind procedure and it is not possible to inspect the sinus mucosa for perforations or pathologies using this technique, hence in the cases of intra-operative perforation, a lateral sinus floor elevation procedure must be performed. Hence, it is wise to always obtain a consent for the lateral technique prior to undertaking the transcrestal procedure. 


\subsubsection{Decision-Making: Simultaneous Versus Staged Approach}

The prerequisite of simultaneous implant placement is the possibility to obtain sufficient primary implant stability $[33,34]$. In cases where primary implant stability cannot be obtained, implants should be placed at a second surgical procedure 2-6 months following sinus floor elevation. Decreased residual bone volume and poor bone density are factors that predispose towards poor primary implant stability. Traditionally, less than $5 \mathrm{~mm}$ was considered as the minimum amount of sub-antral bone height required for simultaneous implant placement. This has. However. been challenged and many recent studies have shown sufficient primary stability in cases with lesser sub-antral bone height. Implant stability has been achieved in these cases by using a tapered implant design, implants with engaging threads, by using the underdimensional drilling protocol and by using bone-condensing drills. Conventionally, it is understood that while undertaking a transcrestal procedure, implants would be placed simultaneously.

Armamentarium for sinus floor elevation consists in addition to the regular minor surgical kit and the implant kit, hand and rotary instruments that are specifically designed for sinus floor elevation. Many companies have introduced kits specifically for this procedure. Some surgeons prefer the use of piezosurgery for access to the lateral window. Additionally, implant companies have also introduced specific burs and elevation kits that reportedly make sinus floor elevation easier to perform. It is ultimately the preference of the surgeon in choosing the armamentarium.

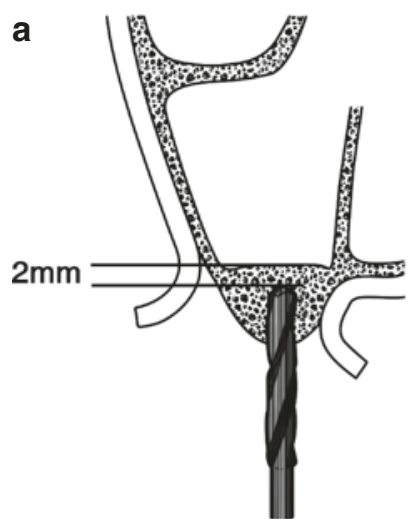

b

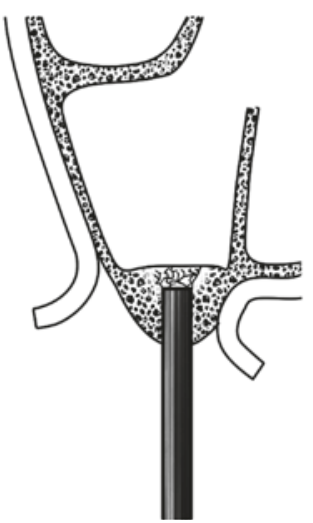

CAssociation of Oral and Maxillofacial Surgeons of India

Fig. 19.11 (a, b, c, d) shows a diagrammatic representation of transcrestal sinus floor elevation. (a) Implant osteotomy made $2 \mathrm{~mm}$ short of the sinus floor. (b) Osteotome introduced through the implant oste-

\subsubsection{Transcrestal Surgical Technique}

After local anaesthesia, a crestal incision is made and the implant osteotomy is performed according to the instructions of the respective implant manufacturer. The osteotomy is made $2 \mathrm{~mm}$ short of the sinus floor. A periapical radiograph can be taken to confirm this. After the depth has been defined, remainder of the implant preparation is done as per the respective manufacturers protocol. Following preparation of the implant bed of appropriate dimension (it is recommended to use an implant of at least $4.0 \mathrm{~mm}$ diameter till further evidence suggests otherwise), an osteotome is introduced into the implant bed and with the help of a mallet, gentle tapping is performed till the sinus floor is fractured. Care should be taken that the osteotome does not perforate the sinus mucosa and enter the sinus cavity. Once the sinus floor has been fractured, a part of the membrane can be visualised to be intact. A careful Valsalva procedure can also be performed to test the patency of the sinus floor. An appropriate graft material is introduced through the implant preparation onto the sinus mucosa. Incremental introduction of the graft material is done, which will push the sinus membrane upwards creating a space between the sub-antral bone and the sinus mucosa. After introducing the appropriate amount of graft material, an implant is inserted to the desired three-dimensional position. Following implant installation, the crestal incision is closed with either a transmucosal or submerged healing protocol. Implant loading is done as per the instructions of the manufacturer, generally within 3 month time. (Fig. 19.11a, b, c, d shows a digrammatic representation of transcrestal sinus floor elevation).
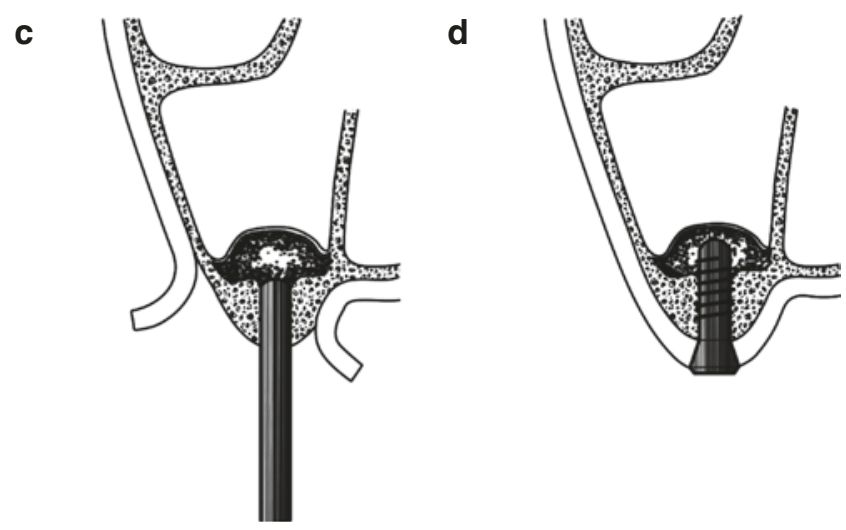

otomy to fracture the sinus floor. (c) Biomaterial introduced to elevate the sinus membrane. (d) Implant placement completed 
A periapical radiograph must be taken at the end of the procedure to confirm no breach of the sinus floor. A wellcircumscribed dome-shaped elevation around the apex of the implant confirms no breach of the sinus membrane. In contrast, if the bone graft is seen around the sinus floor and poorly localised, it denotes a perforation of the sinus floor membrane and in this case, a lateral window approach should be immediately done to clean the sinus cavity.

\subsubsection{Lateral Window Technique}

The lateral window technique can be done alongside lateral and vertical augmentation of the ridge, and with or without simultaneous implant placement. After adequate local anaesthesia, a crestal incision is made with releasing incisions well away from the planned window. A mucoperiosteal flap is elevated and the lateral wall of the maxillary sinus is exposed. A bony window is made according to the local bone anatomy. If vertical septae are present, two bony windows are made on either side of the bony septae. The bony window should be large enough to introduce the graft materials, as well as big enough to permit exploration of the floor, the anteroposterior aspect of the floor to the medial aspect of the maxillary sinus. When the lateral window is made, care should be taken to avoid perforation of the sinus membrane. The lateral window can either be removed from the underlying sinus mucosa or be attached to the to it and pushed inwards. The sinus floor is then slowly teased and reflected away from the floor of the maxillary sinus and elevated using special instruments that resemble a curette to create space for the graft material. It is important to elevate the membrane medially and anteriorly in the areas where augmentation is planned.

(Fig. 19.12a, b, c, d shows diagrammatic representation of the procedure for sinus floor elevation using a lateral window).

If simultaneous implant placement is planned, implant osteotomies should be carried out with the elevated mucosa well protected with an instrument in such a way that the implant drills do not come in contact with the sinus mucosa. Bone graft material is now introduced into the space created by elevation of the membrane. After adequate filling of the space with augmentation material, implants can be placed if planned. The lateral window bone wall (if preserved) can be replaced, or the window can be covered with a barrier membrane. The mucoperiosteal flap is then closed and tensionfree suturing should be placed.

Although, bone graft materials and membranes are commonly used it is not mandatory for the success of sinus floor elevation. Some suggest, elevation of the sinus mucosa and placement of the implant that tents the membrane up, the blood clot that is formed into the space eventually forms bone to surround the implant.

\subsubsection{Complications Following Sinus Floor Elevation}

Sinus perforation is the most common complication following sinus floor elevation. Other complications include (but not limited to) poor primary implant stability, implant migration into the sinus, graft migration into the sinus and intraoperative and post-operative bleeding, wound dehiscence and infection.

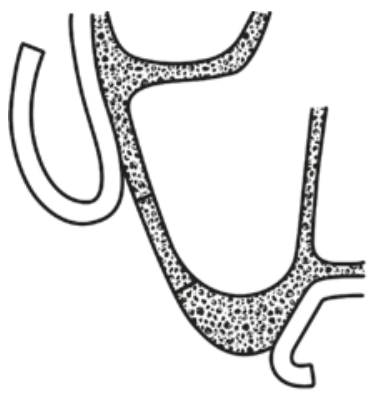

b

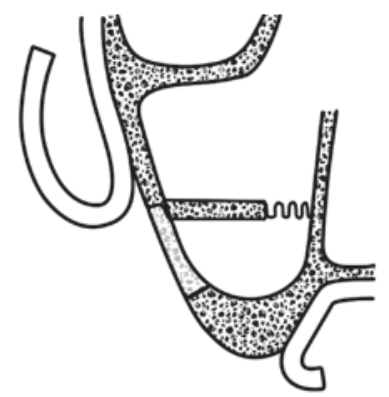

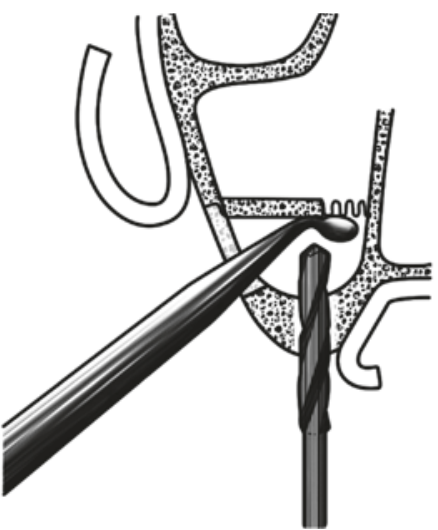

d

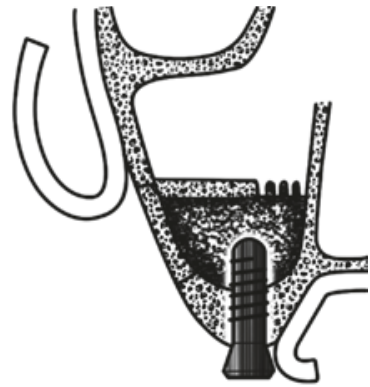

CAssociation of Oral and Maxillofacial Surgeons of India

Fig. 19.12 (a, $\mathbf{b}, \mathbf{c}, \mathbf{d}$ shows diagrammatic representation of the procedure for sinus floor elevation using a lateral window). (a) Mucoperiosteal flap elevated to access the lateral wall of the maxillary sinus. (b) Lateral wall bony window made and in-fractured. (c) Implant osteotomy done. (d) Placement of biomaterial and implant 
Alternatives to sinus floor elevation: The use of short implants [35], angled or tilted implants [3], zygomatic or pterygoid implants [36] are treatment alternatives that may avoid the need for maxillary sinus floor elevation.

\subsection{Suggested Reading}

ITI Treatment guides Volume 5: Sinus floor elevation

ITI Treatment guide Volume 7

ITI Treatment guide series Volume 1-10

ITI Online Academy

Contemporary implant dentistry: Carl Misch

\section{References}

1. Chappuis V, Rahman L, Buser R, Janner SFM, Belser UC, Buser D. Effectiveness of contour augmentation with guided bone regeneration: 10-year results. J Dent Res. 2018;97(3):266-74.

2. Chappuis V, Araujo MG, Buser D. Clinical relevance of dimensional bone and soft tissue alterations post-extraction in esthetic sites. Periodontol 2000. 2017;73(1):73-83.

3. Toljanic JA, Ekstrand K, Baer RA, Thor A. Immediate loading of implants in the edentulous maxilla with a fixed provisional restoration without bone augmentation: a report on 5-year outcomes data obtained from a prospective clinical trial. Int J Oral Maxillofac Implants. 2016;31(5):1164-70.

4. Trbakovic A, Bongenhielm U, Thor A. A clinical and radiological long-term follow-up study of narrow diameter implants in the aesthetic area. Clin Implant Dent Relat Res. 2018;20(4):598-605.

5. Cawood JI, Howell RA. A classification of the edentulous jaws. Int J Oral Maxillofac Surg. 1988;17(4):232-6.

6. Lekholm U, Zarb GA. Patient selection and preparation. In: Branemark PIZG, Albrektsson T, editors. Tissue integrated prosthesis: osseointegration in clinical dentistry. Chicago IL: Quintessence; 1985. p. 199-209.

7. Kumar VV, Sagheb K, Klein MO, Al-Nawas B, Kann PH, Kammerer PW. Relation between bone quality values from ultrasound transmission velocity and implant stability parameters--an ex vivo study. Clin Oral Implants Res. 2012;23(8):975-80.

8. Lindhe J, Bressan E, Cecchinato D, Corra E, Toia M, Liljenberg B. Bone tissue in different parts of the edentulous maxilla and mandible. Clin Oral Implants Res. 2013;24(4):372-7.

9. Mackiewicz Z, Niklinska WE, Kowalewska J, Chyczewski L. Bone as a source of organism vitality and regeneration. Folia Histochem Cytobiol. 2011;49(4):558-69.

10. Jensen SS, Terheyden H. Bone augmentation procedures in localized defects in the alveolar ridge: clinical results with different bone grafts and bone-substitute materials. Int J Oral Maxillofac Implants. 2009;24(Suppl):218-36.

11. Katsuyama H, Jensen SS. Treatment options for sinus floor elevation. In: Chen S, Buser D, Wismeijer D, editors. ITI treatment guide sinus floor elevation procedures. ITI treatment guide. Berlin: Quintessence Publishing; 2011. p. 34-59.

12. Kumar VV, Jacob PC, Ebenezer S, Kuriakose MA, Kekatpure $\mathrm{V}$, Baliarsing AS, et al. Implant supported dental rehabilitation following segmental mandibular reconstruction- quality of life outcomes of a prospective randomized trial. J Craniomaxillofac Surg. 2016;44(7):800-10.

13. Kumar VV, Ebenezer S, Kammerer PW, Jacob PC, Kuriakose MA, Hedne N, et al. Implants in free fibula flap supporting dental reha- bilitation - implant and peri-implant related outcomes of a randomized clinical trial. J Craniomaxillofac Surg. 2016;44(11):1849-58.

14. Bosshardt D, Schenk RK. Bone regeneration: biologic basis. In: Buser D, editor. 20 Years of guided bone regeneration in implant dentistry. 2nd ed. Chicago, IL: Quintessenz; 2009. p. 15-45.

15. Caballe-Serrano J, Munar-Frau A, Ortiz-Puigpelat O, SotoPenaloza D, Penarrocha M, Hernandez-Alfaro F. On the search of the ideal barrier membrane for guided bone regeneration. J Clin Exp Dent. 2018;10(5):e477-e83.

16. Caballe-Serrano J, Munar-Frau A, Delgado L, Perez R, HernandezAlfaro F. Physicochemical characterization of barrier membranes for bone regeneration. J Mech Behav Biomed Mater. 2019;97:13-20.

17. Gruber R, Stadlinger B, Terheyden H. Cell-to-cell communication in guided bone regeneration: molecular and cellular mechanisms. Clin Oral Implants Res. 2017;28(9):1139-46.

18. Caballe-Serrano J, Abdeslam-Mohamed Y, Munar-Frau A, FujiokaKobayashi M, Hernandez-Alfaro F, Miron R. Adsorption and release kinetics of growth factors on barrier membranes for guided tissue/bone regeneration: a systematic review. Arch Oral Biol. 2019;100:57-68.

19. Maestre-Ferrin L, Boronat-Lopez A, Penarrocha-Diago M, Penarrocha-Diago M. Augmentation procedures for deficient edentulous ridges, using onlay autologous grafts: an update. Med Oral Patol Oral Cir Bucal. 2009;14(8):e402-7.

20. Nyman S. Bone regeneration using the principle of guided tissue regeneration. J Clin Periodontol. 1991;18(6):494-8.

21. Dahlin C, Linde A, Gottlow J, Nyman S. Healing of bone defects by guided tissue regeneration. Plast Reconstr Surg. 1988;81(5):672-6.

22. Urban IA, Monje A. Guided bone regeneration in alveolar bone reconstruction. Oral Maxillofac Surg Clin North Am. 2019;31(2):331-8.

23. Buser D, Chappuis V, Kuchler U, Bornstein MM, Wittneben $\mathrm{JG}$, Buser R, et al. Long-term stability of early implant placement with contour augmentation. J Dent Res. 2013;92(12 Suppl):176S-82S.

24. Buser D, Chappuis V, Bornstein MM, Wittneben JG, Frei M, Belser UC. Long-term stability of contour augmentation with early implant placement following single tooth extraction in the esthetic zone: a prospective, cross-sectional study in 41 patients with a 5- to 9-year follow-up. J Periodontol. 2013;84(11):1517-27.

25. Thor A, Wannfors K, Sennerby L, Rasmusson L. Reconstruction of the severely resorbed maxilla with autogenous bone, plateletrich plasma, and implants: 1 -year results of a controlled prospective 5-year study. Clin Implant Dent Relat Res. 2005;7(4):209-20.

26. Dasmah A, Thor A, Ekestubbe A, Sennerby L, Rasmusson L. Marginal bone-level alterations at implants installed in block versus particulate onlay bone grafts mixed with platelet-rich plasma in atrophic maxilla. A prospective 5-year follow-up study of 15 patients. Clin Implant Dent Relat Res. 2013;15(1):7-14.

27. Smolka W. Calvarial grafts for alveolar ridge reconstruction prior to dental implant placement: an update. Oral Maxillofac Surg. 2014;18(4):381-5.

28. Chiapasco M, Casentini P, Zaniboni M. Bone augmentation procedures in implant dentistry. Int $\mathbf{J}$ Oral Maxillofac Implants. 2009;24(Suppl):237-59.

29. Milinkovic I, Cordaro L. Are there specific indications for the different alveolar bone augmentation procedures for implant placement? A systematic review. Int J Oral Maxillofac Surg. 2014;43(5):606-25.

30. Riben C, Thor A. Follow-up of the sinus membrane elevation technique for maxillary sinus implants without the use of graft material. Clin Implant Dent Relat Res. 2016;18(5):895-905.

31. Riben $\mathrm{C}$, Thor A. The maxillary sinus membrane elevation procedure: augmentation of bone around dental implants without grafts-a review of a surgical technique. Int J Dent. 2012;2012:105483. 
32. Duan DH, Fu JH, Qi W, Du Y, Pan J, Wang HL. Graft-free maxillary sinus floor elevation: a systematic review and meta-analysis. J Periodontol. 2017;88(6):550-64.

33. Misch CE. Contemporary implant dentistry. St. Louis: Mosby; 1987.

34. Stefanski S, Svensson B, Thor A. Implant survival following sinus membrane elevation without grafting and immediate implant installation with a one-stage technique: an up-to-40-month evaluation. Clin Oral Implants Res. 2017;28(11):1354-9.
35. Srinivasan M, Vazquez L, Rieder P, Moraguez O, Bernard JP, Belser UC. Survival rates of short $(6 \mathrm{~mm})$ micro-rough surface implants: a review of literature and meta-analysis. Clin Oral Implants Res. 2014;25(5):539-45.

36. Tuminelli FJ, Walter LR, Neugarten J, Bedrossian E. Immediate loading of zygomatic implants: a systematic review of implant survival, prosthesis survival and potential complications. Eur J Oral Implantol. 2017;10(Suppl 1):79-87.

Open Access This chapter is licensed under the terms of the Creative Commons Attribution 4.0 International License (http://creativecommons. org/licenses/by/4.0/), which permits use, sharing, adaptation, distribution and reproduction in any medium or format, as long as you give appropriate credit to the original author(s) and the source, provide a link to the Creative Commons license and indicate if changes were made.

The images or other third party material in this chapter are included in the chapter's Creative Commons license, unless indicated otherwise in a credit line to the material. If material is not included in the chapter's Creative Commons license and your intended use is not permitted by statutory regulation or exceeds the permitted use, you will need to obtain permission directly from the copyright holder. 